\title{
Bop, Rethought: Jazz, culture, and ‘Art Music' in 1950s America
}

\author{
Steven Sladkowski
}

\begin{abstract}
This manuscript was prepared under the supervision of Professor Howard Spring, School of Fine Art \& Music.
\end{abstract}

\begin{abstract}
This paper seeks to discuss of one of the most significant questions in the critical discourse of jazz studies and of ethnomusicology more broadly: How does a musical genre, such as jazz, come to be understood as 'art music'? This paper looks to develop a theory about the concept of 'art music' in relation to jazz, as it is understood in North American culture. In applying this theory, which I call the audience-aesthetic specialization theory, I investigate specifically the stylistic innovations of trumpeter Miles Davis in the mid-fifties, and the place of jazz in American culture of the mid-to-late-fifties more broadly. From this investigation, I attempt to extrapolate a new historiographical understanding of the stylistic changes that facilitated the widespread cultural recognition of jazz as 'art'. Wherever possible, I attempt to nuance my claims using a multi-faceted approach that considers a range of theoretical, aesthetic, and cultural ideas that surround the concept of 'art music' as it relates to jazz.
\end{abstract}

"When people came to hear me, they were going to be coming to hear my music, only." - Miles Davis

$P^{u}$ ut into a modern context, the above statement from Miles Davis is an excellent starting point for a discussion of one of the most significant questions in the critical discourse of jazz studies and of ethnomusicology more broadly: How does a musical genre, such as jazz, come to be understood as 'art music'? This paper looks to develop a theory about the concept of 'art music' in relation to jazz, as it is understood in North American culture. In applying this theory, which I call the audience-aesthetic specialization theory, I investigate specifically the stylistic innovations of trumpeter Miles Davis in the mid-fifties, and the place of jazz in American culture of the mid-to-late-fifties more broadly. From this investigation, I attempt to extrapolate a new historiographical understanding of the stylistic changes that facilitated the widespread cultural recognition of jazz as 'art'. Wherever possible, I attempt to nuance my claims using a multi-faceted approach that considers a range of theoretical, aesthetic, and cultural ideas that surround the concept of 'art music' as it relates to jazz.

\section{The KING IS DeAD: THE LegaCY OF "BIRD"}

"Jazz World Mourns Loss Of Charlie Parker," read the headline of an April 20, 1955 Down Beat news article. ${ }^{2}$ "Acknowledged by most of his contemporaries as the greatest jazzman of modern times," it continued, "the alto sax king died of an acute heart seizure at 8:45 p.m. Saturday, March 12." Indeed, as the strength of the language used in the quotation below suggests, the death of Charlie Parkerthe titan of "modern" jazz and its unrivalled and unparalleled "king"- significantly affected the entire jazz world. In the heartfelt obituary that followed the lead, noted jazz critic Leonard Feather wrote the following:

The agony of living is over for Charlie (Yardbird) Parker. It was an agony he had been ever more reluctant to face during the past year. Those of us who were fortunate enough to know Bird as a friend had the bitter experience of watching him disintegrate, of knowing that it was too late to help him because he no longer cared to be helped or to help himself... What can all the verbal post-mortems do? Charlie Parker has gone, and we can console ourselves only with the thought that his tormented soul has finally found peace. ${ }^{3}$

The untimely, if not unsurprising, demise of Charlie Parker on March 12, 1955-from heart failure, as a result of years of drug and alcohol abuse-marks the beginning of what is perhaps the best-known chapter in the folklore of jazz music. The life of Parker, so the story goes, from his early failures on a Kansas City bandstand to the eventual triumphs at Minton's, and on $52^{\text {nd }}$ Street in New York, is often described by applying many of the romanticized ideals that accompany Western cultural understandings of artistic 'genius': incredible originality and virtuosity, an enigmatic personality, continued perseverance through times of intense personal struggle, and a tragic death. Parker indeed fulfills all of these criteria. The legacy of "Bird" is one of a firebrand personality with an incredibly original and revolutionary artistic voice, passionately displayed time and time again on recordings that are now essential building blocks of the jazz 
canon. He was constantly haunted by the demons of excess and addiction that, though incorrectly thought to give a heightened sense of power and urgency to his playing, would eventually lead to his death.

This presentation of Parker is maintained throughout multiple accounts of jazz history, but perhaps nowhere more explicitly than in the kind of portrayal of Parker in Episodes 7 and 8 of Ken Burns's Jazz. ${ }^{4}$ While jazz history textbooks suggest Dizzy Gillespie provided the music with its intellectual spark, Parker was "bebop's inspiration, the Pied Piper of modern jazz" who cast an enormous - and often destructive-shadow over all jazz musicians. To best exemplify Parker's incredible breadth of influence, one need only look at the outpouring of support and recognition that came from all parts of the jazz world after his death. Towards the end of Feather's obituary in Down Beat, there is a section wholly devoted to tributes from Parker's contemporaries. The names read very much like a who's who of jazz in the 1950s: Duke Ellington, Dizzy Gillespie, Benny Goodman, Norman Granz, and Charles Mingus, to name a few. Again, the language used reinforces the legacy of Bird: "tremendous," "brilliant," "important," "innovation," "the greatest."

As the obituaries and tributes suggest, in March of 1955 the jazz world had no bigger superstar, no greater hero, than Charlie Parker. And for all of the greatness that had been attributed to Parker in life, perhaps even more has been attributed to him in death-and for good reason. Charlie Parker was indeed a talent the likes of which jazz had experienced perhaps only once before, when trumpeter Louis Armstrong burst onto the scene in the late 1920s with his celebrated Hot Five \& Seven recordings. But as huge of an influence as Louis Armstrong was on early jazz music, the influence of Parker's playing is arguably wider in scope and greater in magnitude. While much has been made of Parker's contributions to the jazz aesthetic, little has been said about the symbolic significance of his passing as it relates to broader historical understandings of jazz's stylistic development. To consider Parker's status while living is to recognize his undisputable role as hero to, and figurehead of, the modernist movement in jazz aesthetics. To consider Parker in death is to recognize two significant issues that his passing brought to the forefront of jazz. First, it created an extremely large vacuum, in the leadership of the jazz world's modernist movement. Second, I believe that it symbolically represents the point from which the idiosyncrasies of bebop style began to loosen their stranglehold on jazz aesthetics.

Bebop did not, of course, "die" on the same day as Parker. As Scott DeVeaux suggests in The Birth of Bebop, by the late 1940s the music had developed a distinct commercial viability and appeal, due largely to the mystique and insiders-only atmosphere conveyed by the slang, dress, personalities, and performance practices of its musicians, including Dizzy Gillespie, Thelonious Monk, and Charlie Parker. ${ }^{6}$ This short-lived viability allowed bebop to enter "well-worn commercial channels [where] it followed a familiar pattern of exploitation for a mass consumer audience,"7 much like that of swing in the late 30 s and especially in the 1940s. DeVeaux also notes that the commercial exploitation of bebop in the late 40s eventually led to an "ambiguous aftermath" idea of ambiguity, set into motion in the late 40s, culminates in the immediate aftermath of Parker's death, specifically because of the emergence of the aforementioned vacuum.

While I have pointed out the symbolic significance of Parker's death in 1955 as the historiographical "shift" of the bebop era, it should not be understood as the end of the bebop aesthetic's influence over jazz musicians of the 1950s. It is important to recognize that, while a new generation of jazz musicians had begun to explore different stylistic and aesthetic avenues for jazz music throughout the early 50s (and even as early as 1949), the aesthetics of bebop still served to inform some of these explorations. It is from this generation of explorers - a generation well-versed in and heavily influenced by the language of bebop, but also looking for other modes of creative expression-that jazz eventually found its new "Bird."

\section{It's HaRd To Be CoOl: Miles, Styles, AND THE VICE}

Though not considered widely influential or of any real significance at the time of their recording and initial release, the 1949 and 1950 Birth of the Cool sessions of the Miles Davis Nonet represent one of the earliest divergences from the dominant bebop aesthetic of the late 40s and early 50s. Recordings such as "Move" and "Jeru" are now recognized as some of the first recordings of cool jazz, one of the major styles to emerge in the wake and "ambiguous aftermath" of bebop. "The style was characterized very much by the trumpet playing of Miles Davis who-even during his years with Charlie Parker-had begun to break away from the bebop aesthetic, focusing instead on the midrange of the trumpet, the use of fewer notes, and a greater use of space within solos and arrangements. ${ }^{10}$ It was a style complemented by arranger-conductor Gil Evans, and the eight other musicians who made up the band that recorded Birth. Many of the musicians on these recordings-including pianist John Lewis, alto saxophonist Lee Konitz, and baritone saxophonist Gerry Mulligan-later went on to make their own significant contributions to the cool jazz idiom. Indeed, it continued to be a viable musical aesthetic for much of the first generation of jazz musicians to emerge after bebop, including pianists Dave Brubeck and Lewis, both of whom formed quartets-Brubeck with saxophonist Paul Desmond, bassist Eugene Wright, and drummer Joe Morello in 1951; Lewis with vibraphonist Milt Jackson, bassist Percy Heath and, after Kenny Clarke's brief stint in the group, drummer Connie Kay in 1952 - to further explore the idiom. 
In response to the move away from bebop that cool jazz represented, there emerged in the mid-fifties another stylecharacterized by groups such as the Clifford Brown-Max Roach Quintet, The Jazz Messengers, and the various groups of Miles Davis_-generally referred to as hard bop. Again, it is Miles Davis who- as with the Birth of the Cool recordings and cool jazz - played a significant role in establishing the style, as exemplified on recordings such as "Walkin'," from 1954's Walkin'. 'Hard bop was very much the antithesis of cool jazz, and featured somewhat of a return to the faster tempos, eighth-note-laden solos, and hard swing that characterized much of the music of the bebop era. Much like Birth of the Cool, the group that recorded Walkin' contained some of the most significant performers to later contribute to the hard bop idiom, including trombonist J.J. Johnson and pianist Horace Silver. Indeed, just as cool jazz had provided a new generation of jazz musicians a set of aesthetics different from bebop, hard bop too developed into a viable aesthetic avenue for that same generation of jazz musicians, some of whom were dissatisfied or discontented with the aesthetics of cool jazz.

The emergence of hard bop and cool jazz marks the beginning of a significant trend in jazz that has had a prolonged effect on its musicians, fans, critics, and academics. Thought not specifically discussing jazz, this trend is what musicologist Leonard Meyer has, in Music, The Arts, and Ideas, called "a multiplicity of styles":

The coming epoch (if, indeed, we are not already in it) will be...a period characterized not by the linear, cumulative development of a single fundamental style, but by the coexistence of a multiplicity of quite different styles in a fluctuating and dynamic steady-state. ${ }^{12}$

Hard bop and cool jazz are two of the earliest styles that signal the "coming epoch" that Meyer had described and were followed in the late 50 s by styles that included modal jazz, free jazz, and soul-jazz. While jazz has historically always had some degree of stylistic multiplicity-one thinks of the continued success of New Orleans-era revival bands and contemporary reincarnations of Swing Era big bandsthe level of innovation and influence maintained by the emergent sub-styles of the 1950s has a significant and prolonged effect on the very ways in which jazz is understood and defined. By the time of Charlie Parker's death, both cool jazz and hard bop had fully emerged as legitimate aesthetic avenues of expression that did not rely squarely on bebop, and had blown open the doors for a host of later innovators-such as Ornette Coleman-to further explore the music's aesthetic potentialities. Indeed, as Birth of the Cool and Walkin' suggest, this opening of aesthetic avenues was due largely to the influence of Miles Davis, who by 1954 had begun to position himself as the foremost innovator at the head of the jazz world.
Interestingly, Davis's contributions to both of the idioms came at two influential but very different points in the trumpeter's career. At the time of the Birth of the Cool recordings, Davis, like many jazz musicians active in the late forties and early 50s, was hooked on heroin. Jazz's widespread heroin problem-very much a product of the influence of Charlie Parker, with whom Davis had played as late as $1950^{13}$ - had become an issue of concern amongst many of the club owners and critics who comprised much of the business side of the jazz world. In 1950, Down Beat ran an expose on the problem, which significantly affected Davis's reputation amongst club owners and critics. As John Gennari has noted, the opinions held by individual jazz critics-especially in the 1950 s-often had a significant effect on the broader public opinion and reception of musicians who were "struggling to articulate a creative vision and negotiate the marketplace."14 Said the trumpeter in his autobiography:

Toward the end of the year Down Beat magazine wrote this story about how heroin and drugs were ruining the music scene and they talked about how Art Blakey and myself had been busted in Los Angeles. Well, after that, everything was out in the open and I could hardly buy a music job. The club owners just froze me out. ${ }^{15}$

There is no question that the public exposure of his heroin problem in the pages of Down Beat did further damage to his already-shaky career. A drug problem, if kept private, was dangerous but easily mediated by Davis, ensuring the upkeep of his reputation amongst club owners and critics. A public exposition of a drug problem, however, could lead to nothing short of blackballing. As he later stated in his autobiography, "it was bad enough playing the kind of music we played, but with a habit, it was worse. People started looking at me another way, like I was dirty or something. They looked at me with pity and horror and they hadn't looked at me that way before." 16 As Davis suggests, heroin was a scourge that plagued jazz musicians in their private lives, while also negatively affecting the necessary construction and marketing of their images within the public consciousness.

For Miles Davis, heroin not only affected his public image, but also his ability to perform and record regularly. By 1952, recording and performance dates decreased dramatically, as Davis's dependence on heroin and reputation as a "junkie" grew. Tom Lord's comprehensive Jazz Discography contains only a handful of entries for Davis between 1952-53. At most, Lord lists eight recording sessions taking place in this timeframe under Davis's leadership, while there are seven listings for live or radio broadcast dates. ${ }^{17}$ Indeed, by 1953 Davis was in the darkest depths of the kind of addiction that affected a host of his contemporaries-including Philly Joe Jones, John Coltrane, and Sonny Rollins - and that would lead, two years later, to 
the untimely and tragic demise of Charlie Parker. Fortunately, by 1954, Davis had begun to reverse his situation and repair his public image. Quoted in Miles: The Autobiography, he notes in hindsight the year's significance, stating:

\begin{abstract}
Nineteen fifty-four was a great year for me-although I didn't realize how great it was at the time. I had kicked my habit and was playing better than I ever played, and a couple of the albums that were released that year, like Birth of the Cool and Walkin', made everybody-the musicians-sit up and notice me again, more than ever before. The critics' heads were still someplace else, but a few people were starting to buy my albums [my emphasis]. ${ }^{18}$
\end{abstract}

Of interest especially is Davis's own recognition of the negative effect that heroin addiction had on his playing. By '54 when he reemerged-albeit quietly amongst an audience that consisted mainly of his contemporaries-he had kicked the destructive heroin habit that had bogged down his production in 1952 and 53, and found a new focus and drive, exemplified on his playing on tracks such as "Walkin'." While Walkin' had represented for Davis an important aesthetic achievement that forced his peers to acknowledge his significance, it is worth noting Davis's concession that "critics' heads were still someplace else." While Davis's relationship with a vast majority of critics was touchy-atbest $^{19}$, the fact that he noticed the lack of critical reception given to Walkin', enough to explicitly mention it years later suggests that his reputation, while beginning to turn itself around, was not fully repaired in the eyes of many jazz critics in 1954. This full-scale critical reversal would come a year later, in 1955, only a few months after the death of Charlie Parker.

\section{'ROUND MIDNIGHT: NEWPORT AND THE 1955 DOWN BEAT CRITICS' POLL}

In even the most conservative accounts of his life and music, 1955 is recognized as a watershed year in the career of Miles Davis. By 1954, his peers had begun to take notice of the significance and weight carried in his unique voice-both as a soloist and composer, as exemplified on Birth of the Cool and Walkin'. Still reeling from the death of Parker in July of 1955, the jazz community turned its collective sight to Newport, Rhode Island, where impresario George Wein had-for the second consecutive year-organized the Newport Jazz Festival. A huge outdoor event with performances; workshops; discussion panels; and jam sessions all involving a great many of the most popular jazz musicians of the day, the Newport festival was, by no accident, set in one of the United States' most highlyesteemed cultural centres. On the bill for one of the Sunday, July 17 performances was the newly reemerged and heroinfree Miles Davis, playing as part of all-star sextet. The group, comprised of Davis on trumpet; Zoot Sims on tenor saxophone; Gerry Mulligan on baritone saxophone; Thelonious Monk on piano; Percy Heath on bass; and Connie Kay on drums, seems only to have come together on this one occasion to perform a series of bebop standards, which included "Hackensack," "Now's The Time," (a tribute to Parker) and-perhaps most significantly for Davis-Monk's " Round Midnight." Though noting an overall "miserable" sound system in his August 24, 1955 write-up of the festival, Down Beat reviewer-later editor-Jack Tracy noted that, "Miles played thrillingly and indicated that his comeback is in full stride. Heath, too, shone; as did all members on the ensuing "Now's The Time." It was Miles, however, who captured most ears." ${ }^{20}$ While in the review Tracy makes specific mention of Miles's playing on "Hackensack" and "Now's The Time," it is interesting to note that there is no mention of the performance given by Davis on Monk's "'Round Midnight" from the same afternoon session. It was this performance if "'Round Midngith" that history has judged most important to Miles' resurgance.

As suggested at the beginning of this section, a crosssection of some of the most significant works of jazz scholarship regarding Miles reveals a widespread recognition of his Newport performance-and playing on "'Round Midnight" especially — as the turning point of the trumpeter's career. $^{21}$ Interestingly, little has been written about why this performance marks such a significant turning point. Most mention of the event is done in passing, as in Lewis Porter's biography of tenor saxophonist John Coltrane, who writes only that, "[Miles'] appearance with a rhythm section at the second Newport Jazz Festival in July 1955 woke everybody up to his brilliance," 22 and John Gennari's Blowin' Hot and Cool, which notes, "[Miles'] performance with Thelonious Monk at the Newport Jazz Festival that summer garnered rave reviews." 23 Scott DeVeaux and Gary Giddins's recent, and incredibly comprehensive, university-level textbook Jazz makes a more concerted-albeit still-surface levelrecognition of the performance. The textbook reads:

In the summer of 1955 , Davis made a brief but much-
acclaimed appearance at the Newport (Rhode Island) Jazz
Festival, creating a stir with his version of Monk's
"'Round Midnight." It was the first time most critics and
fans had ever seen a Harmon mute. On the basis of this
performance, Davis's successful comeback was sealed.

Not only is the passage brief in its mention of the performance's significance, it also makes a glaring mistake regarding Davis's use of the Harmon mute. It is the same mistake made by Davis biographer Jack Chambers when recounting the Newport performance in Milestones. ${ }^{25}$ While Davis does, on the studio recording of "Round Midnight," use the distinctive sounding mute during the melody and his corresponding solo, the Newport recording is played 


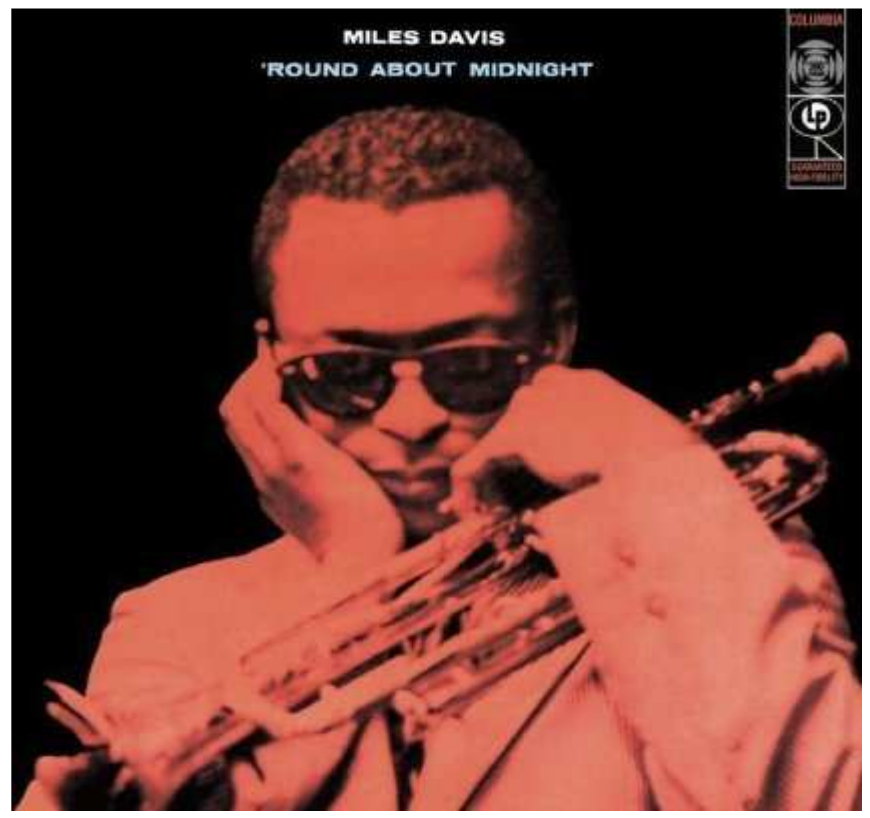

Figure 1: Miles Davis, 'Round About Midnight (Columbia Records, 1957)

unmuted throughout. ${ }^{26}$ Missing too from the Newport performance is the orchestrated ensemble passage, which occurs on the 1956 studio recording between Davis's and tenor saxophonist John Coltrane's solo. This was surely omitted at Newport due to the jam session nature of the afternoon performance, which in all likelihood was staged with little to no rehearsal between the six performers that took part. Indeed, this performance comes from the period in 1955 before Davis had hired Coltrane ${ }^{27}$, and before the orchestrated break became part of Miles's stock arrangement of the composition. ${ }^{28}$ It is worth discussing some of the other intricacies and peculiarities of the Newport performance of "'Round Midnight," in order to gain some insight into why it is widely-recognized to be the performance that so successfully sealed Davis's comeback, and "woke everyone up to his brilliance."

One of the more notable differences on the Newport recording is that of instrumentation. While "Hackensack," "Now's The Time," and the other pieces performed involved the five other members of the all-star group, the rendition of "'Round Midnight" is performed instead by a quartet. On this recording Davis is backed only by Monk on piano; Heath on bass; and Kay on drums; three players Davis knew well, as he was, by 1955, a veteran of the New York scene due in large part to his work with Parker. The reduced number of performers allows Davis to take an incredibly spacious approach throughout, both on his phrasing of the melody and on his solo. It is an approach that is beautifully complimented by the sparseness that characterizes the piano style of Monk, who on this recording provides a delicate and primarily chordal accompaniment upon which Davis crafts his solo.

More significant, though, is the very character and shape of Miles Davis's solo. While "Walkin" and "Move" showcase Davis's distinctive mid-range sound, they also employ many of the harmonic riffs and licks that characterize the bebop style. ${ }^{29}$ These clichés, as Davis himself saw them, were exactly the kinds of dead musical ends that-starting especially on Davis's forays in modality in the late fifties such as Milestones and Kind of Blue-he had begun to recognize in his playing and increasingly attempt to move away from. His solo from Newport sounds very much like a precursor to this later work, and less like the standard bop fare that characterizes much of his earlier work. Indeed, Davis's playing on "'Round Midnight" sounds not like a unique organization, interpretation, and rendering of beboporiented licks that fit the fast-moving chord changes of a piece like "Walkin'," but more like an original melodic composition based on the given chord changes, in this case, to "'Round Midnight." 30 The compositional style of solo is one that defines much of the trumpeter's work with both his first and second quintet, and this recording seems to be one of the earliest examples of the melodic approach to playing that soon became Davis's trademark. It is important, though, to also recall Davis's own recognition of his commercial achievements on Walkin' and Birth of the Cool. These two albums were, and indeed remain, two of the best recordings that exemplify Davis's style in the early fifties during his struggles with heroin. At the time of the Newport performance, these records would have surely been the bestknown Davis recordings amongst the vast majority of critics, musicians, and fans that made up the festival's audience. It was this voice of Miles Davis-predominantly influenced by bop, and heard so clearly on Walkin' and, to a lesser-extent, Cool-that audiences and critics alike were most accustomed to hearing, and had expected at Newport. Instead, they were treated to a quick glimpse at the confident, mellow, spacious, mature voice of the "new" Miles Davis.

While Davis's solo from Newport gives some of the earliest recorded insight into his explosive musical development that occurred throughout the mid-to-late 1950s, it is perhaps more noteworthy because of the chain of events that followed the performance's conclusion, and the festival's end. In the very same issue of Down Beat that contained Jack Tracy's glowing review of Davis's Newport performance, the results of the magazine's third-annual Critics' Poll were released. In the trumpet category was a result that, in the words of Nat Hentoff, "surprised the international jazz community" 31 : Miles Davis had tied Dizzy Gillespie - the trumpeter he had replaced only a few years earlier in Charlie Parker's working quintet_for first place. ${ }^{32}$ As the applause at the end of the recording, Davis's strong showing in the Critics' Poll, and the historical recounting of the event suggests, the jazz community enjoyed its glimpse of a heroin-free Miles Davis and was eager for more. On top 
of gaining the kind of critical and popular recognition that had been comparatively rare in 1954 and the years before, the exposure granted to Miles from the festival led to one of the most significant occurrences in the entire history of jazz music. Quoted in Jack Chambers's extensive biography of the trumpeter, Milestones, then-editor of Metronome magazine Bill Coss wrote in 1956 of Davis's Newport performance, "[that] whatever Miles did was provoking enough to send one major record label executive scurrying about in search of him after the performance was over.",33 The executive to whom Coss refers is George Avakian from Columbia Records, who, upon hearing Davis at Newport in 1955, promptly signed him to an exclusive recording contract. ${ }^{34}$ It is this shift from Prestige-one of the smallmarket independent labels so central to the documentation of music from the bebop era-to the major label Columbia that, in 1955, began to truly elevate the cultural status of jazz as art music, and of Miles Davis as its central artistic innovator.

\section{Miles is MakiN' WaX: Columbia, Collaboration, AND "Studio AUdio ART"}

Miles Davis's shift to Columbia had a series of profound and far-reaching implications on many of the central facets of jazz music's creation, production, and consumption, as they were understood in the 1950s. In signing with Columbia, Davis was provided access to a great many resources and opportunities, allowing him a level of artistic freedom that had been unavailable - and unthinkable - to any of his contemporaries and predecessors. Perhaps most significantly, Columbia provided Davis with access to a national distribution network unmatched by any of the smaller record labels - such as Prestige, Riverside, and Blue Note-that made up much of the lion's share of the jazz recording industry during the forties and fifties. This was an opportunity that Davis did not let go unnoticed, and would make full use of throughout his lengthy recording career. As he noted in his autobiography:

One of the basic things that I understood was that success in this industry always depends upon how many records you sell, how much money you make for the people who control the industry. You could be a great musician, an innovative and important artist, but nobody cared if you didn't make the white people who were in control some money. The real money was in getting to the mainstream of America, and Columbia Records served the mainstream of this country. ${ }^{35}$

Davis's recognition of the need for mainstream recognition and success to solidify his place as an artistic innovator is an incredibly interesting remark, because it necessarily acknowledges and problematizes one of the central beliefs that informs many supporting arguments and claims of jazz as art music: a divorce from popular commercialism. As
DeVeaux has suggested, jazz need not-and perhaps cannot—be wholly divorced from its commercial aspirations to necessarily be considered art. ${ }^{36}$ While DeVeaux's claims support his excellent accounting for the emergence and development of bebop in the 1940s, they hold true too for much of the jazz music created and sold in 1950sespecially the music of Miles Davis:

As a musician and as an artist, I have always wanted to
reach as many people as I could through my music. And I
have never been ashamed of that. Because I never thought
that the music called "jazz" was ever meant to reach just a
small group of people, or become a museum thing locked
under glass like all other dead things that were once
considered artistic. I always thought it should reach as
many people as it could, like so-called popular music, and
why not? I never was one of those people who thought
less was better; the fewer who hear you, the better you
are, because what you're doing is just too complex for a
lot of people to understand. A lot of jazz musicians say in
public that they feel this way, that they would have to
compromise their art to reach a whole lot of people. But
in secret they want to reach as many people as they can,
too. ${ }^{37}$

Not only did Columbia wholly represent the best opportunity for his music to reach new audiences and untapped musical markets, the label actually encouraged and supported Miles Davis's uncompromising artistic vision. Far from forcing the trumpeter to "compromise [his] art to reach a whole lot of people," George Avakian and the other "white people who were in control" 38 at Columbia Records instead allowed Miles free reign of access to Columbia's resources, in order to maximize both the aesthetic and commercial values of his music. This was achieved through a great many different avenues, the very least of which was Davis's exploration and experimentation with Columbia's state-of-the-art recording studios and recording technology.

By the time Miles signed with the label in 1955, Columbia had long-since established itself as a leading innovator in the recording industry. Nowhere is this better exemplified than in the well-documented, and oft-cited patenting of the long-playing record (LP) in 1948-LPs provided the opportunity to accurately capture the lengthy performances of jazz musicians, both in live and studio settings, which had previously been too long for earlier formats. In the 1950s, new technologies and concepts-most notably tape recording techniques such as overdubbing and splicing-were being compounded with the use of the LP format on many of Columbia's recordings, including several of Davis's earliest works for the label. As jazz scholar Lewis Porter has noted of Davis's recording process with Columbia:

Recording for Columbia was more formal [than Prestige]. Each number was recorded for as many takes as needed to 
get it right, and usually all the tape was saved. Complicated arrangements were a plus-they added to the polish of the finished product. And splicing was fine if the saxophone solo on one take was good and the trumpet solo on the other was preferred, or even in the middle of a solo...Far from looking at editing as a distortion of true jazz, Davis delighted in the new possibilities of tape, and he tended to trust his producer's instincts [emphasis added]. ${ }^{39}$

Davis's use of and delight in the "new possibilities" of tape-possibilities that are often colloquially termed "studio magic"-figures prominently in much of his work with arranger-conductor Gil Evans, and will be discussed in-depth later in this section. First, however, the concept of studio magic provides an opportunity for the necessary consideration of the uses and significance of recordings and the recording studio in the bebop era.

From its inception, jazz has primarily been a music that is consumed by the public in various live performance settings-whether in the concert theatres, clubs, dance halls, or other venues that have housed its musicians throughout the twentieth and twenty-first centuries. While the dissemination and tracking of the music's stylistic development is often tied to specific compositions, solos, and performances that have been preserved on recordings, recordings themselves are often given an inflated status by posterity-especially through the work of critics and academics-in order to make sense not only of jazz's stylistic development and performance practices, but also to better understand the social significance and contexts of the performance-based music. While today, recordings by such luminaries including King Oliver; Jelly Roll Morton; Louis Armstrong; Duke Ellington; Fletcher Henderson; Dizzy Gillespie; and Charlie Parker-to name only a few-are often regarded as "essential listening" for any new jazz fan, one should instead consider these recordings for their historical raison d'être.

As a music that is primarily performed live, even the most popular and historically significant recordings in jazz's history up to, and including, those of the bebop erarecordings such as "West End Blues," "East St. Louis Toodle-oo," and "Ko-Ko"-were created with the intention of attracting popular attention to and encouraging attendance for the live performances of musicians in dancehalls, such as the Savoy Ballroom and the Cotton Club, and later in the clubs on Fifty-Second Street. Concerns with the independent commercial viability and success of a record-while recognized by musicians such as Duke Ellington and Dizzy Gillespie-were secondary to the recording's ability to draw crowds to a group or soloist's next live performance. They were, for lack of a better conceptual term, more about advertising than artwork. In order to better understand this claim, let us consider the realities of the recording session during the bebop era.
The 1942 recording ban-which significantly ruptured for most audiences the ongoing documentation, and consumption, of the stylistic developments in jazz (such as the "moldy figs" who were so blindsided by bebop) —is often lamented because of its creation of a bothersome stylistic continuity gap. Indeed, to the unprepared ear expecting a style more reminiscent of swing, the music of Parker, Monk, and Gillespie seems to be an incongruous next link in the chain. While Scott DeVeaux has accounted for much of the gap in The Birth of Bebop, the constraints on musicians and producers imposed by the recording ban significantly affected the jazz recording process well into the 1950s. The imposition of constraints is perhaps best exemplified in the term so often used to describe the developmental sparkplug of bebop, but which can also be used to describe the overwhelming approach to the vast majority of bebop era recordings: the jam session.

The jam session: an informal, hastily organized affair in which a group of players got together to "blow," with littleto-no rehearsal and minimal musical arrangement. This 'authentic' type of jazz performance-as vehemently championed by bop's early fans-transferred easily into the studios of the small, independent labels that rushed to record the beboppers when the recording ban ended in 1945. Aside from Blue Note, these independents lacked the kind of money that could cover union wages for the kind of rehearsal time needed to realize more complex and ambitious compositions in any studio setting. They instead relied heavily on contrafact compositions, based on familiar chord progressions - "Rhythm" changes and twelve-bar blues especially - that were easily performed, and performed well, by a group of musicians within the first few takes. Producers showed little interest in post-production, often happy to have captured what was perceived to be a 'spontaneous' and 'authentic' musical occurrence. Indeed, these kinds of bop recordings, and the majority of those that came before, are the kind of recording that ethnomusicologist Thomas Turino has called high fidelity music.

Turino notes that, "high fidelity recording in a studio aims to make the recording process 'invisible' or at least to downplay production processes so that the recording will be received as a faithful representation of a lifelike musical performance. ${ }^{40} \mathrm{By}$ creating the perception that the recording was an 'authentic' bebop performance, the jam session approach worked to reinforce the idea that bebop was a music best experienced and understood through live performance. This was a fabricated authenticity, because as Turino notes, "achieving what is perceived as a live sound in the studio involves a good deal of technological intervention," 41 especially in microphone placement done in order to pick up 'live' spots in the room that will sound through on the recording. One need only consider the meticulously crafted and expertly controlled 'live' sound created by engineer Rudy Van Gelder-as heard on many of 


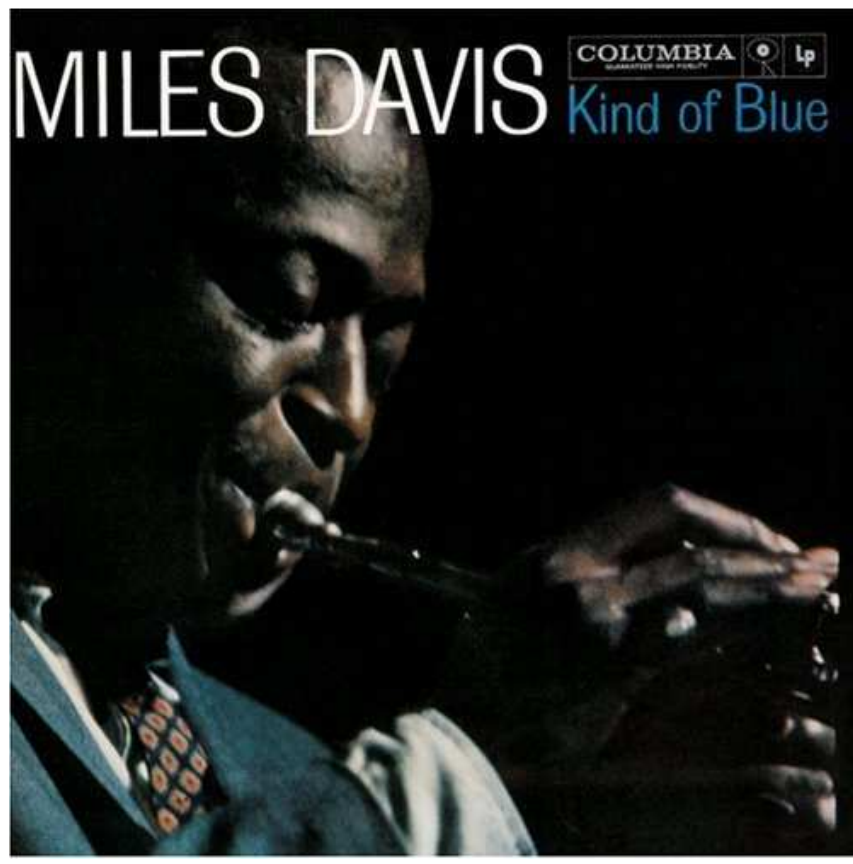

Figure 2: Miles Davis, Kind of Blue (Columbia Records, 1959).

the finest Blue Note records from the 1950s and 60s-to understand this concept. ${ }^{42}$ A consideration of Turino's concept suggests that the jam session style of recording was done by producers who hoped to capture exactly the 'authentic' live performances that lay at the heart of the cultural constructions of the bebop movement. In presenting bebop this way, producers and record labels reinforced the incorrect critical and cultural assumption that bebop was not a music that could be consumed seriously in a recorded format. It was instead a music that was widely perceived to be wholly dependent on an individual's live experience of the jam session.

Though recording studios provided the opportunity of creating serious music for broader public consumption-an opportunity that Miles Davis explicitly explored starting in 1955-it existed as an acknowledged, but relatively insignificant, afterthought in the vast majority of jazz recordings made well beyond the advent of bebop. The use of the recording studio to create serious art intended for broader public consumption was, as I have shown, a central tenet of Miles Davis's approach to the realization of projects and compositions during his time with Columbia Records. This was partly due to technological advances and distribution opportunities provided by the label, but underlying these two factors is the fact that the Columbia could afford to absorb all of the associated costs of studio luxuries. These luxuries included extended studio time for extra takes and in-depth rehearsal, the use of arrangers and extra musicians, and the hiring of producers for in-depth preand post-production. They were indeed luxuries that Prestige and most other smaller labels could not provide - for lack of either financial or aesthetic interest - to the vast majority of jazz musicians in the mid-fifties, even one as influential, groundbreaking, and popular as Miles Davis.

While Davis remained under contract to Prestige until 1956, Lewis Porter notes that the first recording session Davis had with Columbia-then-leading what has come to be known as the first great quintet, consisting of Davis; John Coltrane; Red Garland on piano; Paul Chambers on bass; and Philly Joe Jones on drums-was on October 27, $1955 .{ }^{43}$ The output of these sessions, combined with two later sessions in June and September of 1956, was released by Columbia on March 4, 1957 and is one of Davis's best and most popular releases: 'Round About Midnight. ${ }^{44}$ On the $2001 \mathrm{CD}$ reissue of the release, the types of luxuries provided by Columbia to Davis are exemplified, specifically the use of multiple studio sessions to record a single release. The ' 57 release features six tracks that provide a well-rounded snapshot of the Davis quintet, including three bop tunes ("'Round Midnight," "AhLeu-Cha," and "Tadd's Delight"), popular compositions ("All Of You" and "Bye Bye Blackbird"), and a traditional piece ("Dear Old Stockholm," arranged by Stan Getz). On the 2001 reissue, four extra tracks cut during the very same '55 and '56 sessions are included ("Two Bass Hit," "Little Melonae," "Budo," and "Sweet Sue, Just You"). The inclusion of these tracks shows that Davis was using the studio not to record jam sessions, but instead to perfect the group's sound and repertoire, in order to ensure a strong and successful artistic and commercial debut for Columbia.

The extra effort and time spent in the studio paid off for Davis, with "'Round Midnight" becoming, as Porter has noted, "a jukebox hit in black neighborhoods in its 45 RPM release." 45 The popular success of 'Round About Midnight ensured Miles' good standing with Columbia executives, which allowed him full access to resources, in order to realize his later, more complex projects. ${ }^{46}$ That Davis took three separate recording sessions to record more material than necessary is indicative enough of the new-found opportunities provided by Columbia, but 'Round About Midnight was only the first in a series of significant artistic and commercial successes by Davis for the label throughout the late $1950 \mathrm{~s}$.

1957 was an important year for Davis not only because it is the year of his recorded debut and first commercial success with Columbia, but also because it marks the beginning of an incredibly fruitful three-year creative partnership with Gil Evans. Evans, a Canadian-born arranger-pianist-conductor, had first met Miles during his days as an arranger for the Claude Thornhill Band. He was a man who, Davis noted, "was one of the only ones who could pick up on what I was thinking musically." 47 Evans was also one of the major influences on Davis's musical thoughts in 1949 and 1950, when Davis conceptualized and recorded Birth of the Cool, with a nonet that contained many of the instrumental voices and timbres that Evans had arranged for 
in the Thornhill band. ${ }^{48}$ While the recorded output of the prolonged Davis-Evans partnership consists mainly of the three albums recorded and produced between 1957 and 1959, the artistic and commercial achievements exemplified by Miles Ahead (1957), Porgy and Bess (1958), and Sketches of Spain (1959) remain some of the greatest in the music's history, and represent, I believe, the musical point from which the greater cultural recognition of jazz as art music began. While Evans had worked with Davis briefly for Birth of the Cool, it was not until Davis signed with Columbia that he was able to hire Evans for an extended period of time, allowing Evans to craft the intricate arrangements for all three recordings. The partnership seemed to come at a perfect time for Davis's producer at Columbia, George Avakian, who, quoted in Larry Hicock's Castles Made of Sound, said:

I wanted to present Miles in a different setting [after 1957's success with 'Round About Midnight], and it was important to make it a good one, that would be memorable and sell records, because that's the bottom line, after all. We didn't just want to be artistic successes-I wanted to see Miles become a financial success...He was finishing up his Prestige contract with the quintet, so there was a lot of quintet material coming out onto the market rather quickly. Therefore, obviously, we had to go in a different direction, and what should it be? Well, I loved the sound of the nine-piece band, but then I thought, why not make it bigger than that? I've got the budget to do it, and that would make a more spectacular splash for Miles [emphasis added]. ${ }^{49}$

If the above quotation suggests anything, it is that by 1957 , both Columbia and Miles Davis were eager to create a different kind of jazz music than the bebop blowing sessions, and that could be both commercially and artistically successful. To realize the sorts of ambitious projects that characterize the Davis-Evans partnership, Avakian and Columbia were more than willing to invest the necessary time, money and resources needed, in order to ensure the full commercial and artistic success of the recordings-as a consideration of the recording, production, and reception of Miles Ahead indeed confirms.

While not at all the first bebop-era soloist to perform in the context of a big band/orchestral setting-one thinks immediately of Charlie Parker With Strings (Verve, 1950)Miles Ahead represents the kind of artistic undertaking that would have been wholly impossible in the jazz world without the time and "magic" that Davis had access to in Columbia's studios. Much like 'Round About Midnight before it, Miles Ahead was recorded over more than one recording session. Hicock has observed that Miles Ahead was an artistic project to which Columbia provided, "more studio time than most jazz albums would normally be allocated,"50 allowing for Evans to meticulously orchestrate the settings upon which Davis's solos were based. During the recording, Evans "often insisted on doing take after take" ${ }^{, 51}$ of intricate passages, which created a wealth of extra material and alternate takes for producer George Avakian to work with in the postproduction of Miles Ahead. Again, it is Larry Hicock who notes the significant role played by Avakian-the person responsible for making sense of the many hours of audio-in crafting the sound of Davis and the nineteen-piece ensemble:

At the time Miles Ahead was recorded, the only way to edit music was to cut the master tape with a razor blade, eliminate the unwanted portion or replace it with an alternating take, then splice the pieces back together. Another device was overdubbing. With the advent of multi-track recording, it became possible to record the master on one track and save the second track for the overdub. A true pioneer in audio "post-production," George Avakian used his skills courageously on Miles Ahead and to great advantage. Four of the album's tunes contain solos that were dubbed in by Miles several months after the band sessions. More remarkably, the original master is said to contain over two hundred splices. It is a patchwork of material gleaned not only from the alternate takes but also the rehearsals, which Avakian had also started recording. ${ }^{52}$

The quasi-perfectionist approach taken by Davis, Evans, and Avakian during the recording of Miles Ahead-and in the later collaborative works Porgy and Bess and Sketches of Spain-exemplifies the changing role and increased significance of the recording studio in jazz music that was manifesting in the 1950s. For Miles Davis, the recording studio was a serious tool through which ambitious, extendedlength musical projects-musical compositions-could be successfully realized. Unlike the bebop era, which focused mainly on the creation of high fidelity music recordings, in the fifties the recording studio emerged as place for jazz musicians to realize the sorts of compositions and projects that Turino has called studio audio art:

[Studio audio art] is recorded music that is patently a
studio form with no suggestion or expectation that it
should or even could be performed live in real time.
Being freed from ideologies of authenticity involving live
performance, studio audio art has extremely different
dynamics, goals, and potentials from those of the other
three fields. This field involves the manipulation of taped
sounds, synthesized sounds, or digital technology for the
creation of sonic art objects that exist only in
electronically reproducible form (recordings, sound files)
and in which the goal is the creation of the recorded piece
itself-to be listened to after it is completed, much as a
painting is to be viewed once it is finished.

While I believe that studio audio art is still a viable option for the description of recordings such as Miles Ahead, there is a need to adapt and nuance Turino's definition as it relates specifically to jazz music in the fifties. Perhaps most significant is Turino's idea-one that is touched upon by Lewis Porter in the block quotation presented on page 
eighteen-of notions of "authenticity involving live performance." The idea, as it relates to jazz, is that 'real' jazz music is that which is recorded or performed in a high fidelity setting. As soon as 'intrusive' post-production techniques-such as those employed by George Avakian on Miles Ahead-are used, the recordings become an inauthentic representation of jazz music. This is an incredibly short sighted and altogether spurious claim. There is no doubting that any of the music created by Miles Davis and Gil Evans in this period is jazz. One need only listen to "Blues For Pablo" (from Miles Ahead) or "Summertime" (from Porgy and Bess) for this to be confirmed. ${ }^{54}$ Far from making the finished product a less-authentic example of jazz music, the use of "studio magic" and post-production techniques allowed for the full realization of the music as it was envisioned and imagined by the performers, composers, and producers, personified in this case by Avakian, Davis, and Evans. Instead of relying on fabricated ideas of "authentic spontaneity," Avakian and Davis expertly combined two aspects of what ethnomusicologist Bruno Nettl has recognized as the continuum of musical creationimprovisation and composition. ${ }^{55}$ Indeed, the incorporation of techniques of overdubbing and tape splicing (compositional techniques) led to the creation a more complete and fully-realized artistic sound recordingperhaps more fitting a descriptor than "studio audio art"that generally was not an option for most musicians during earlier eras. ${ }^{56}$ The public indeed recognized the undeniable artistic achievements of Davis's early Columbia recordings. As Hicock notes:

Miles Ahead was an immediate success on every levelartistic, commercial, financial, aesthetic, and critical. It bolstered Columbia's image in the jazz market. It enhanced George Avakian's reputation not only as a hitmaker but also as a producer of jazz as art music. It solidified the emergence of Miles Davis as the foremost jazz voice of his time. ${ }^{57}$

Miles Ahead-and to a lesser-extent, 'Round About Midnight-proved undeniably to the jazz world that the recording studio was no longer a place to create advertisements for the serious art created and best consumed, up to that point, primarily in jazz clubs. It was, instead, a place where jazz musicians could conceptualize, understand, create, and realize the full extent of the music's artistic capacity, the likes of which were impossible to capture only through live performance.

\section{The Prince of Darkness: Marketing Jazz IN POSTWAR AMERICA}

While the music contained on Miles Davis's late-fifties releases recast the role of commercial records and the recording studio for jazz musicians, the artistic merit of his music alone did not solidify his position as jazz's foremost artistic innovator. Nor were his groundbreaking artistic achievements for Columbia the sole reason of the music's dramatic rise in cultural status, as I will show. Columbia's marketing of Davis's music was strongly complemented by the label's marketing of Miles Davis, the Prince of Darkness: a strong, modern, masculine African-American man. Columbia's construction and marketing of this image fit also with the efforts of a great many critics, who worked tirelessly to elevate the status of the music in the utter cultural mêlée of postwar America.

To consider any aspect of American culture in the postwar period is a daunting and incredibly complex task. It is arguably the most influential decade in twentieth-century American history, if only because it is in the postwar period where the oppressive cultural norms-the norms so challenged and protested in the tumultuous 1960s-were established and solidified. It is the period of white flight and Civil Rights; of Cold War conformity and McCarthyism; of "Father Knows Best" and "the Problem with No Name"; of economic expansion and unabashed consumerism; of television, dishwashers, and vacuum cleaners. It is the era of American modernism. As I have discussed in the earlier pages of this paper, modernist thought is central to any discussion of jazz music, especially in the fifties. Indeed, it was the central ideological framework from which the construction of the organic and evolutionary jazz tradition emerged. As John Gennari has suggested, in the fifties a new group of American critics-contributing articles to magazines such as Down Beat, Metronome, The New Yorker, Esquire, and Playboy — crafted a discourse that:

\footnotetext{
...trumpeted [jazz's] intellectual legitimacy by employing tropes of age and maturation. According to the new gospel, the music and its audience had grown up: a fan culture driven by raw, undisciplined teenage enthusiasm had been supplanted by more cerebral modes of adult appreciation. $^{58}$
}

Jazz - to Nat Hentoff, Ralph Gleason, Whitney Balliett, Dan Morgenstern, Gunther Schuller, and others-was the true American intellectual art form. No longer, they believed, could American culture maintain the prevalent, but outdated and wholly inaccurate, view of jazz as a music created solely to accompany dancing, drinking, and debauchery. The music of "raw, undisciplined teenage enthusiasm." It was, instead, "grown up" art music that commanded serious, "more cerebral modes" of presentation, consumption, and critical discussion. Paraphrasing cultural theorist Andrew Ross, Gennari notes that the modernist aspirations of jazz critics in the postwar era were part of a much broader cultural trend, in which:

[American] Cold War intellectuals considered it a matter of political and moral responsibility to nurture and defend a "serious" national culture, safeguarding it from the contaminating influence of political radicalism, 
sentimental populism, and an intellectually bankrupt mass culture. $^{59}$

Understood as an autonomous American art form, the modernists believed jazz could serve exactly these sorts of purposes. What the music needed, however, was the opportunity to enter into the consciousness of the "serious" American cultural mainstream. What jazz needed was an updated image. A "new look" that was able to show off its intellectual, artistic side while reversing the torrid, underworld assumptions that so informed the mainstream's cultural constructions of the music. Nowhere was this attempt at reversal more prevalent than in the event that reestablished the career of Miles Davis: the Newport Jazz Festival.

Started by George Wein in 1954, the Newport Jazz Festival-held in the Rhode Island bastion of the Eastern Seaboard's largely-Euro American upper class-is perhaps the most significant cultural institution that helped to establish jazz as an art form worthy of upper-class cultural recognition. It is almost impossible to overstate the significance of the role played by the Newport in the realization of many of the goals of the modernist movement in jazz. The festival's importance is best discussed, I believe, on page 210 of Blowin' Hot and Cool, where Gennari notes:

In Newport...jazz symbolized the refining impulses of an educated, curious, urbane, and diverse audience. Jazz's cultural capital accrued by virtue of its association with northeastern social elites, its propaganda value as a form of interracial "democratic" popular culture, and its symbolic status as a serious American "art" legitimated by intellectuals and jazz critics who seized upon it as a bulwark against a perceived threat of mass-entertainment youth culture, especially rock'n'roll. For many of the new breed of jazz musicians who considered themselves at least as cultured as the audiences they performed for, the well-manicured New England landscape represented welcome change from the hurly-burly pace of the customary jazz life. Jazz musicians of the 1950s thought of themselves as educated artists and as contributors to an important American tradition. ${ }^{60}$

What the Newport festival provided was the desperatelyneeded, nationally recognized, and culturally-esteemed venue in which the "educated artists" of jazz music could display their "legitimated" and "serious American art." It was the place where jazz musicians could escape the harsh realities - of addiction, exploitation by club owners, and grueling tour schedules - that shaped the "hurly-burly pace of the customary jazz life." Newport was the place where the initial goal of the beboppers could finally be realized. It was the place where jazz could-in the eyes of its critics, fans, and musicians-shed its cultural associations with, and connections to, the slippery concept of "popular music." In the mid-fifties, there was perhaps no one better representative of jazz's "new look" than Miles Davis. Free from the addictions that hampered and destroyed the careers of many of his peers, The Prince of Darkness-perhaps the most financially successful jazz musician of the era-could often be seen wearing only the finest in tailored clothes and driving a European sports car, all the while with his arm around the beautiful Frances Taylor, a dancer and Davis's then-wife. He was distant, handsome, and utterly "cool." Indeed, he epitomized completely all of the masculinistmaterialistic ideals that so informed every facet of mainstream American culture in the postwar period. Yet as an African American, he was the sort of cultural icon that evoked an extreme sense of ambivalence from the American public. In a time when speeches, marches, and sit-ins began to mobilize popular support for the Civil Rights movement's calls for the end of racial injustice, Davis's image was very much subject to the twin notions of fear and fascination that so characterized mainstream America's relationship with its most prominent African American citizens.

The aspect of fascination lies, as Ingrid Monson has suggested, largely in the culturally constructed, Euro American notions of the "hip" African American jazz musician. The construction, which Monson terms "white hipness," is intricately connected "[to] a style of black masculinity that held, and continues to hold, great appeal for white audiences and musicians." 61 It is very much the style that was portrayed and embodied by Miles Davis in the postwar era. It is the underlying idea of Columbia's marketing strategy for his commercial releases, exemplified in a consideration of the way in which Davis's image is constructed in two of his most famous album covers (Figures 1 and 2). ${ }^{62}$ Figure 1 captures the trumpeter in an iconic pose from the cover of 1957's 'Round About Midnight, wearing a pair of sunglasses that further adds to the feeling of guarded nonchalance-of "hipness"portrayed by Davis in the photograph. The photographer's use of a red lens helps very much to add to this mystique, ensuring the viewer's attention is directed not to ideas of Davis as musician and artist, but instead to Davis's persona-the Prince of Darkness.

The opposite is true of Figure 2, the cover of Davis's classic 1959 release Kind of Blue. The photograph is a fullcolour shot of Davis playing the trumpet, presumably in midsolo. Here he is still very much the "cool," "hip" Prince of Darkness, but the true focus of the photograph is on Miles Davis the Musician: a confident, composed artist wholly devoted to the spontaneity of the moment.

To best exemplify the notion of fear as it relates to the perceptions of jazz in American culture more specifically, let us consider a another iconic-perhaps even notoriousimage, from the November 8, 1954 cover of Time magazine (Figure 3). ${ }^{63}$ The image is of pianist Dave Brubeck, superimposed on a surrealist, cool-coloured background where pairs of suspended hands play the instruments of his quartet-saxophone, piano, bass, and drums. The historical and cultural significance of this image comes not from what 
is implied by the image itself, but instead from the questions raised and answers suggested regarding the social motives for putting Brubeck-a Euro American jazz musician-on the cover instead of an African American, such as Miles Davis. One of the most influential current events magazines of the fifties, Time carried the sort of cultural weight and influence that could - much like the Newport Jazz Festivalhelp to establish jazz as art music. In choosing Dave Brubeck as the first jazz musician to be featured on the magazine's cover, Time's editors unknowingly exposed perhaps the most significant issue that confronted modernists in their attempts to elevate the music's status: the issue of race.

While African Americans have always been at the heart of the music's stylistic innovation, jazz-like all twentiethcentury musics affected by ongoing processes of transculturation - is by no means a racially exclusive music. From the beginning, it has been a music shaped and influenced not only by aspects of African musical traditions, but also by aspects of Latin, Caribbean, and European traditions. Its performers have been an equally diverse group, which serves as a testament to the egalitarian nature of the music. Without question, it is a music that, at its best, works to bring individuals and groups together regardless of race, class, and gender. However, there is no doubting that jazz musicians were significantly affected by the realities of life in an American society suffering badly from the sickness of Jim Crow. Recognizing this, the racial issues that surround this image of Brubeck-especially concerning the concepts of cultural ownership and appropriation-must necessarily be considered.

As the above image suggests, when mainstream America thought of jazz in the postwar period, it was not Miles Davis's image that came to mind-even though he was, if not by ' 54 then surely by ' 55 , widely recognized as the music's foremost innovator. It was instead the image of the pianist Brubeck, who-as critic Nat Hentoff wrote-“was respectable enough for Time because he had studied with [the French composer] Milhaud, was a favorite among collegians-and was white."64 Brubeck-while very much an integral part of the "new look" and "respectability" of jazz also represented by Miles Davis-did not evoke the same sort of cultural ambivalence as Miles, for the very simple reason that he was not African American. To put an African American man on the cover of Time magazine-especially a jazz musician, given the opinions still widely held by much of the cultural mainstream-seems, in 1954, to have been an almost unthinkable option. This is, of course, due largely to the turbulent racial climate of the era. While events such as Brown v. Board of Education, and the sit-ins, marches, and bus boycotts of the early Civil Rights movement had begun to challenge many of the social norms regarding race in the Cold War era, the appearance of Brubeck's photo on the cover of Time suggests that the American cultural mainstream-while willing to accept jazz as a serious art music-was unwilling to accept the fact that African
Americans had a central role in creating jazz's artistic merit in the first place.

Perhaps there is no better recognition of what I will, for now, call the quasi-appropriation of jazz by the American cultural mainstream, than by Miles Davis:

\begin{abstract}
A lot of white critics kept talking about all these white jazz musicians, imitators of us, like they was some great motherf-ckers and everything. Talking about Stan Getz, Dave Brubeck, Kai Winding, Lee Konitz, Lennie Tristano, and Gerry Mulligan like they was gods or something... Now I'm not saying here that these guys weren't good musicians, because they were; Gerry, Lee, Stan, Dave, Kai, Lennie, all of them were good musicians. But they didn't start nothing, and they knew it, and they weren't the best at what was being done [emphasis added]. ${ }^{65}$
\end{abstract}

Miles' opinion is significant because it seems to be representative of the perception of appropriation and blinding racial bias regarding events, such as the Brubeck cover, that seem to have been shared by many of jazz's more raciallyaware and supportive critics. Indeed, while the creation of jazz music has always been a colourblind pursuit, many of the business aspects of the music have disproportionately favoured individuals of Euro American origin, especially in terms of economic reward. While it is easy to read Brubeck's feature on the cover of Time as an indicator of this idea of appropriation, such a reading is absolutely inconsistent with the central motives of the modernist drive for jazz's acceptance, and the realities of jazz music.

If the goal of the modernists was, in part, to bring jazz's message of egalitarianism into the intellectual mainstream of American cultural life, perhaps the biggest obstacle in the realization of that goal was not cultural appropriation, but instead the overwhelming mainstream resistance to the social concept of egalitarianism-not only to African Americans, but also to women, homosexuals, and other groups-during the postwar era. To suggest that jazz is appropriated, however, is to disregard the fact that jazz is-and always has been-a multicultural music. It belongs to no one cultural group, but instead to all those who create, consume, and strive to understand the music. While the ugly realities of postwar racial inequality are wholly to blame for strange and unfortunate events such as that of the Time cover, I think it is impossible to suggest-as many of the most thoroughly postmodern jazz scholars may-that such events were done with malicious intent.

\section{ROLl OVER, BEETHOVEN: ROCK 'N' ROLL, JAZZ, AND AUdienCE-AESTHETIC SPECIALIZATION}

As the jazz aesthetic began to shift during the bebop erawith its focus on soloists playing rhythmically intricate and harmonically complex melodies and solos-so too did its audience, in order to better understand, appreciate, and 


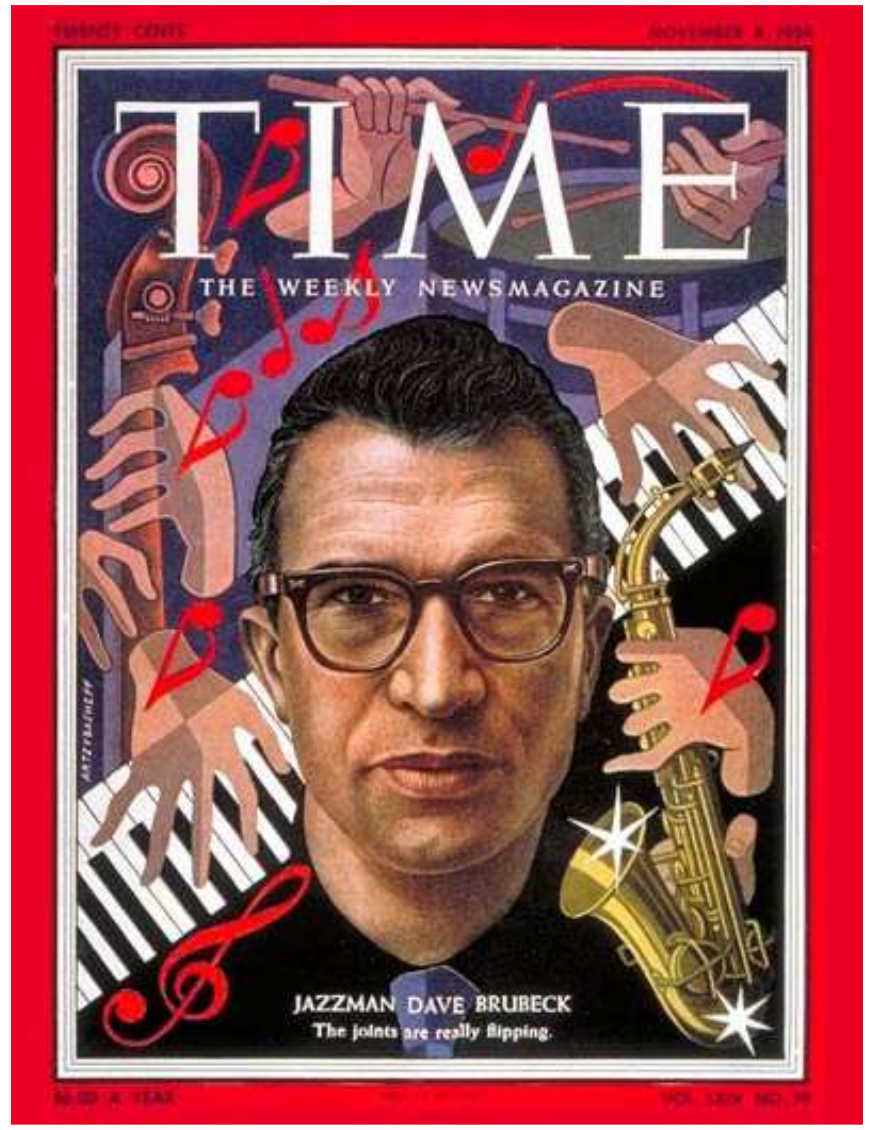

Figure 3: Dave Brubeck, Time Magazine, ca. Nov. 8, 1954

consume the new music that was being created. The commercial dominance of swing, however, maintained the widespread belief that jazz was music for dancing, and not to be "seriously" considered as art. Indeed, the cultural recognition of jazz as art music was badly hindered by the ongoing popularity and economic success of swing as dance music, leading to the continuation of what historian David Stowe has called "the old bebop dilemma: whether jazz is primarily a music for listening or dancing." 66 In the midfifties, this dilemma was resolved completely by an unlikely culprit: rock and roll.

As DeVeaux has suggested, to consider jazz as 'art music' does not require a divorce from commercial-populist motivations that so inform the creation and consumption of music in the capitalist-driven, commerce-oriented market realities of Western culture. However, to discuss jazz in the postwar era is to recognize the very significant fact that, by Charlie Parker's death and Miles Davis's emergence in 1955, jazz-while still an economically viable music with commercial appeal-had completely ceased to be popular music. While this is a development that began during the bebop era, it is not until the recognition and exploitation of the commercial viability of rock and roll-throughout the 1950 s - that this development was fully manifested. As jazz ceased to be popular music in the fifties, so too emerged the opportunity for it to be culturally recognized as something more: for it to be recognized as art music. Due largely to the cultural recognition and commercial establishment of rock and roll as the new form of popular dance music in the 1950 s, jazz was free to be recognized as music meant not for dancing, but instead for listening.

Much like the death of Charlie Parker does not wholly represent the end of bebop, the popular and commercial success of Elvis Presley, Chuck Berry, and the other early rock and rollers does not fully explain jazz's emergence as art music. To suggest this would be to belittle the incredibly beautiful-and indeed artistic_-music created by the many virtuosic musicians who came before the 1950s, and who figure prominently in any discussion of the history of jazz music. What the emergence of rock and roll does represent, in relation to jazz, is the solidification of a broader concept regarding cultural understandings of "art music," which I will call the audience-aesthetic specialization theory of musical style. As the success of Miles Davis's Columbia recordings shows, there existed in the fifties a market for the complex, more cerebral music being created by jazz musicians of the era. This marked was created by the emergence of an audience that thoroughly enjoyed jazz, while refusing to recognize it as the popular music of the American public. It is in the space between the distinct notions of "popular" music and musics that are commercially viable, but not "popular," where the specialization phenomenon occurs.

It can perhaps be said that the understanding of specific musical styles in Western culture is mediated largely by two factors. First, we must consider the artistic potentiality of a musical work. That is, the importance or significance of an individual artist's creative contribution to a style, as it is broadly conceptualized. This has been exemplified throughout by Miles Davis's contributions to the style called "jazz." ${ }^{67}$ Secondly, we must determine-by considering a range of socio-cultural, economic, and aesthetic factors-the extent to which an artist's contribution resonates with its specific audience, who are responsible for consuming, judging, and understanding all creative contributions to that particular style. This is determined by considering what will henceforth be called the audience potentiality of an artistic creation. In describing these two potentialities, it is important to realize that they are mutually influential and profoundly codependent in occurrence. To be sure, an artist cannot truly determine the audience potentiality of a stylistic contribution, due to the largely subjective nature of aesthetic experience and appreciation. Nor can an audience member truly impose opinions of artistic potentiality on an artist during that artist's creation of a piece. However, an artist's individual contribution to a style facilitates the formation of subjective aesthetic opinions within audience members, who necessarily consume and understand that contribution. And the formation of subjective aesthetic opinion-as an artist is also 
an audience member consuming other contributions-is, in itself, absolutely necessary for any individual contribution to a particular style.

In creating works that seek to appeal to a wide variety of aesthetic opinions and viewpoints-as in the music of the swing era, which appealed to a great many individuals who enjoyed dancing, but were not necessarily aware of the artistic potential realized by the music's individual soloistsartists are often able to realize the maximum audience potentiality of a given creation. Through attempting to realize this maximum, artists create what I have referred to throughout as popular music. Alternatively, though, artists can create works that willingly limit the audience potential by creating and applying aesthetic principles that, often due to their complex nature, are understood and consumed by a smaller audience. It is here, in the creation of a more aesthetically complex music that is understood and consumed by a smaller audience-such as that of bebopwhere the intricacies of the specialization phenomenon begin to take effect.

If it can be agreed that the relationship between artist and audience are indeed codependent and mutually influential, and that certain musical styles develop and realize audience and artistic potentiality in different ways, it is worth discussing how a musical style can be commercially viable without being considered "popular music." One of the most significant aspects of the specialization phenomenon is the ease with which a specialized musical style can create a supportive commercial market-or niche market-for itself. Due to this codependent relationship of audience and artist, it follows that as a more specialized musical style is developed, so too will there be a more specialized audience to consume and understand it. Again, one need only consider the development of bebop to understand this concept. Perhaps even more significant is the idea that when there exists a specialized and supportive commercial market, musicians are able to further explore the artistic potentiality of an alreadyspecialized style. It is through the creation of this type of music-music that explores a style's artistic potentiality for consumption and understanding by an already-specialized audience-where a musical style such as jazz is able to be commercially viable without being considered "popular music."

It was at this point of specialization where jazz music was in 1955, when Charlie Parker passed away and Miles Davis performed "'Round Midnight" at the Newport Jazz Festival. It was this drive for aesthetic exploration that encouraged the use of the recording studio as an artistic tool, allowing Davis to create his Columbia masterpieces and arguably assuring his status as jazz's foremost artistic innovator in the postwar period. It is the point, too, from which we can begin to account for the emergence-and mutual coexistence-of sub-styles such as free jazz, modal jazz, and hard bop, which occurred at various junctures throughout the fifties. And, indeed, it is from this point of jazz's overall development-not during the bebop era, but well into the postwar period-where the music was culturally recognized as art music.

\section{CONCLUSIONS}

Throughout the course of researching, writing, editing, and rewriting this paper, several new ideas and potential areas for research have developed. So too have the holes, errors, and new thoughts regarding my original arguments and ideas. Perhaps most significant is the need to further develop the theory I have suggested for understanding the concept of 'art music' in Western culture. The theory must be developed with more significant consideration of marketing and other business concepts as they apply to the recording industry, and to the creation and consumption of music more generally. This will allow for a better understanding of how niche aesthetic markets are able to develop and survive.

Upon completion of this paper, I began to notice the same trends that I discovered in 1950s jazz also exist in other genres-most notably in American bluegrass music. While I don't look to suggest that my theory is a catchall theory for all Western musics, I am sure that a comparative study of the development of jazz and bluegrass would yield fascinating, and unexpected, results. The interconnectedness of musical genres in the Western world-and perhaps of the whole world-is a topic that should be at the very top of the list for all scholars interested in music, regardless of the discipline from which they approach their research and scholarship.

Incomplete, too, is my discussion about the intricacies of certain lines and solos in the development of Miles Davis's trumpet style. This discussion could easily be expanded upon through the inclusion of notated transcriptions of the phrases and passages in question. The inclusion of transcriptions would allow for a more accurate discussion of the influence of bebop era chromaticism, modality, and other stylistic developments that were informing jazz musicians in the 1950s.

The development of style also raises questions about historiography and power relations as they apply to sociocultural understandings of "jazz." The development of jazz in the fifties presents a perfect point of discussion for concepts such as modernism, race, class, and gender that have all figured prominently in the emergent fields of jazz studies, improvisation studies, and cultural studies. While I have briefly touched upon some of these concepts in the above pages, entire books can-and have-been devoted to these concepts as they relate to jazz music.

My work builds on a small, but ever-growing, body of research conducted by an incredibly diverse and insightful group of individuals who are working to fully understand the musical importance and cultural significance of jazz. For those who create, consume, and attempt to understand it, jazz is more than just music. It has, if a study of the music's history can tell us anything, perpetually helped multiple 
generations of humans to better understand themselves and the world they live in. It is for this reason that jazz must continue to be discussed, challenged, and recast-regardless of the academic discipline or method of approach. To do so will only strengthen the incredible legacy of the music and its musicians, while ensuring that no stone is left unturned in the musical and cultural quarry called jazz.

\section{ACKNOWLEDGMENTS}

Thanks to Dr. Howard Spring, SOFAM, University of Guelph, for his invaluable guidance and insightful comments-and for perpetually tolerating my neurosis during this paper's research, writing, and editing phases.

\section{ENDNOTES}

${ }^{1}$ Miles Davis with Quincy Troupe, Miles: The Autobiography (New York, New York: Touchstone Books, 1989), pg. 163.

2 Author Unknown, "Jazz World Mourns Loss Of Charlie Parker," in Down Beat Magazine, April 20, 1955, pg. 5.

${ }^{3}$ Leonard Feather, "No More Agony: Parker Finally Finds Peace," in Down Beat Magazine, April 20, 1955, pg. 6.

${ }^{4}$ See especially the dramatic introduction given Parker at the beginning of Episode 7 ("Dedicated to Chaos") and throughout Episode 8 ("Risk"), especially in the introduction and later chapters.

${ }^{5}$ Scott DeVeaux and Gary Giddins, Jazz (New York, New

York: W.W. Norton \& Company, 2009), pg. 285.

${ }^{6}$ Scott DeVeaux, The Birth of Bebop: A Social and Musical

History (Berkeley, California: University of California Press, 1997), pg. 438.

${ }^{7}$ Ibid.

${ }^{8}$ DeVeaux, Bebop, pg. 443.

${ }^{9}$ See Audio Appendix, tracks 1 and 2 ("Move" and "Jeru" by the Miles Davis Nonet) for an example of the cool jazz style.

${ }^{10}$ See Audio Appendix, track 3: "Now's The Time" by

Charlie Parker Quintet (with Miles Davis).

${ }^{11}$ See Audio Appendix, track 4: "Walkin'" by the Miles Davis All-Stars (Prestige, 1954).

${ }^{12}$ Leonard B. Meyer, Music, The Arts, and Ideas: Patterns and Predictions in Twentieth-Century Culture (Chicago, Illinois: The University of Chicago Press, 1967), pg. 98.

13 Tom Lord, The Jazz Discography, Vol. 5, s.v. Davis, Miles (Redwood, New York: Cadence Jazz Books, 1993), pg. D114.

${ }^{14}$ Gennari, pg. 199.

${ }^{15}$ Davis, pg. 140.

${ }^{16}$ Davis, pg. 163.

${ }^{17}$ Lord, pp. D115-D117.
${ }^{18}$ Davis, pg. 188.

${ }^{19}$ See Davis, especially pgs. 76 and 83, and Gennari, especially pp. 200-203.

20 Jack Tracy, "Newport!" in Down Beat Magazine, August 24, 1955 (Vol. 22, No. 17), pg. 24.

${ }^{21}$ See DeVeaux/Giddins, pg. 374 especially.

${ }^{22}$ Lewis Porter, John Coltrane: His Life and Music (Ann Arbor, Michigan: University of Michigan Press, 1999), pg. 97.

${ }^{23}$ Gennari, pg. 201.

${ }^{24}$ DeVeaux \& Giddins, pg. 374.

${ }^{25}$ Jack Chambers, Milestones: The Music and Times of Miles Davis (Toronto, Ontario: University of Toronto Press, 1983), pg. 206.

${ }^{26}$ See Audio Appendix, track 5: "'Round Midnight" by Miles Davis Quartet (Davis, trumpet; Thelonious Monk, piano; Percy Heath, bass; and Connie Kay, drums) from the $2^{\text {nd }}$ Annual Newport Jazz Festival, 1955 (from Columbia Records' 2005 reissue of 'Round About Midnight, Disc 2) and track 6: "'Round Midnight" by Miles Davis Quintet (Davis, trumpet; John Coltrane, tenor saxophone; Red Garland, piano; Paul Chambers, bass; and Philly Joe Jones, drums) from 'Round About Midnight (Columbia Records, 1957).

${ }^{27}$ Porter, pg. 98.

${ }^{28}$ On Disc 4 of the recent Davis box set The Legendary Prestige Quintet Sessions (Universal Music Group, 2006), there is an alternate take of "'Round Midnight" which also includes the orchestrated break. I have not yet been able to access the liner notes in order to determine the date of this recording, however given the fact that it was first issued on the Prestige box set (instead of the 2005 Columbia reissue of Round 'About Midnight), the orchestrated break was perhaps a part of the quintet's working repertory while Davis was still under contract to Prestige. This contracted lasted through 1956, though Davis was recording for Columbia by 1955. The Prestige outtake has been included as track 7 of the Audio Appendix.

${ }^{29}$ Listen to the use of space and the way Davis ends his lines at 1:42, 2:28, and the short motif that begins at 2:51 and corresponding lines that end at 3:13 of "Walkin'."

${ }^{30}$ In contrast to "Walkin'," listen to the way Davis uses space and finishes his lines on the Newport recording of "'Round Midnight," especially at 1:14, 1:47, and 2:10.

${ }^{31}$ Nat Hentoff, "Miles," in Down Beat Magazine, November 2, 1955 (Vol. 22, No. 22), pg. 13.

32 “Third Annual Critics' Poll," in Down Beat Magazine, August 25, 1955 (Vol. 22, No. 17), pg. 9. Davis and Gillespie both received fifty votes, a full twenty votes more than the next trumpeter on the list, Louis Armstrong.

${ }^{33}$ Chambers, pg. 206. 
${ }^{34}$ See both Larry Hicock, Castles Made of Sound: The Story of Gil Evans (Cambridge, Massachusetts: Da Capo Press, 2002), pg. 82, and Porter, pg. 97.

${ }^{35}$ Davis, pg. 205.

${ }^{36}$ As DeVeaux notes on page 16 of the introduction to The Birth of Bebop: "For the black jazz musicians of the 1930s and 1940s [...] mass-market capitalism was not a prison from which the true artist is duty-bound to escape [as many critics portrayed it to be]. It was a system of transactions that defined music as a profession and thereby made their achievements possible." I would argue further that the recognition and investigation of commercial motivations are central to any discussion of Western music in any genre.

${ }^{37}$ Davis, pg. 205.

${ }^{38}$ Davis, pg. 205

${ }^{39}$ Porter, pg. 102.

40 Thomas Turino, Music as Social Life: The Politics of Participation (Chicago, Illinois: University of Chicago Press, 2008), pg. 68.

${ }^{41}$ See Turino, Chapter 3, especially pp. 71 and 77. I suggest the idea of "false authenticity" in regard to the cultural constructions of bebop that underlay the recording approach taken by engineers and producers, and not to suggest that bebop recordings are at all inauthentic reproductions of the way in which the music was performed.

${ }^{42}$ See Richard Cook, Blue Note Records: The Biography

(Boston, Massachusetts: Justin, Charles \& Co., 2001), pp. 67-69.

${ }^{43}$ Porter, pg. 101.

${ }^{44}$ Liner Notes, 'Round About Midnight (Columbia Records, 2001 CD Reissue), pg. 3.

${ }^{45}$ Porter, pg. 102.

${ }^{46}$ See Hicock, Chapter 7 ("Miles Ahead"), pp. 86 and 113 especially.

${ }^{47}$ Davis, pg. 184.

${ }^{48}$ Stephanie Stein Crease, Gil Evans: Out of the Cool: His Life and Music (Chicago, Illinois: A Cappella Books, 2002), pg. 179.

${ }^{49}$ Hicock, pg. 86.

${ }^{50}$ Hicock, pg. 90.

51 Ibid.

${ }^{52}$ Hicock, pg. 91. While Hicock mentions a 1998 Avakian interview with NPR as a supporting source for this claim, I have yet been able to access a supporting source to back-up Hicock's numerical estimations of overdubs and splices used to create the music on the recording. It is reasonable to assume that the liner notes to Miles Ahead could provide some insight, but I have been unable to access them as of the writing of this paper. Given that Miles was performing tour dates as of the release of 'Round About Midnight during this time period (see CD liner notes of 'Round About Midnight, pg. 7), it is altogether reasonable to assume that Hicock's claims of overdubbing and tape splicing are accurate, given the hectic, performance-based lifestyle that was still the reality for jazz musicians in the $1950 \mathrm{~s}$.

${ }^{53}$ Turino, pg. 78.

${ }^{54}$ See Audio Appendix, Track 8: "Blues For Pablo" by Miles Davis and Gil Evans Group from Miles Ahead (Columbia Records, 1957).

${ }^{55}$ Bruno Nettl, The Study of Ethnomusicology: Thirty-One Issues and Concepts (Urbana, Illinois: University of Illinois Press, 2005), pp. 30-31: Nettl suggests that both improvisatory and compositional methods - such as soloing and post-production-are both essential parts of the creative processes in musics of the twentieth century, whether considered "art" music or not.

${ }^{56}$ While there are some noteworthy exceptions-one thinks primarily of Duke Ellington's attempts in the 20s and 30sthe advancement of recording technology allowed for the realization of extended creative projects such as Miles Ahead in unparalleled ways.

${ }^{57}$ Hicock, pg. 92.

${ }^{58}$ Gennari, pg. 180.

${ }^{59}$ Gennari, pg. 168.

${ }^{60}$ Gennari, pg. 210.

${ }^{61}$ Monson, pg. 402.

${ }^{62}$ Figure 1 taken from

<http://www.jazz.com/assets/2007/12/25/albumcoverMilesD avis-RoundAboutMidnight.jpg> accessed April 14, 2009.

Figure 2 taken from

<http://www.1000recordings.com/images/artist-d/davismiles-234-1.jpg> accessed April 14, 2009.

${ }^{63}$ Figure 3 taken from <http://www.time.com/time/covers/0,16641,19541108,00.ht $\mathrm{ml}>$ accessed April 14, 2009.

${ }^{64}$ Quoted in Gennari, pg. 165. Interestingly, Gennari notes that Brubeck was on the cover in 1955, which is a mistake. He has probably taken his dates from the Hentoff article, which appeared in the fall 1955 edition of the Chicago Review (see Gennari, pg. 411 - Chapter 4 Notes).

${ }^{65}$ Davis, pg. 156.

${ }^{66}$ Stowe, quoted in DeVeaux, Bebop, pg. 439.

67 "Jazz" should still be considered a blanket term used for a series of interrelated musical sub-styles, as I suggested in the early pages of this paper. It does, however, still serve in broader discourse to describe a certain set of aesthetic principles (improvisation, small ensemble-based, etc.) that inform the creation of a specific style of music, and it is this second definition I am considering in using the term here to discuss the specialization phenomenon. 


\section{REFERENCES}

Chambers, Jack. Milestones: The Music and Times of Miles Davis. Toronto, Ontario: University of Toronto Press, 1983.

Cook, Richard. Blue Note Records: The Biography. Boston, Massachusetts: Justin, Charles \& Co., 2001.

Davis, Miles with Quincy Troupe. Miles: The Autobiography. New York, New York, Touchstone Books, 1989.

DeVeaux, Scott. The Birth of Bebop: A Social and Musical History. Berkeley, California: University of California Press, 1997.

DeVeaux, Scott, and Gary Giddins. Jazz. New York, New York: W.W. Norton \& Company, 2009.

Gennari, John. Blowin' Hot and Cool: Jazz and Its Critics. Chicago, Illinois: The University of Chicago Press, 2006.

Heble, Ajay. Landing On The Wrong Note: Jazz, Dissonance, and Critical Practice. New York, New York: Routledge Books, 2000.

Hicock, Larry. Castles Made of Sound: The Story of Gil Evans. Cambridge, Massachusetts: Da Capo Press, 2002.

Lord, Tom. The Jazz Discography, Vol. 5, s.v. Davis, Miles. Redwood, New York: Cadence Jazz Books, 1993.

Martin, Henry and Keith Waters. Essential Jazz: The First 100 Years (Second Edition). Boston, Massachusetts: Schirmer, 2005.

Meyer, Leonard B. Music, The Arts, and Ideas: Patterns and Predictions in Twentieth-Century Culture. Chicago, Illinois: The University of Chicago Press, 1967.

Monson, Ingrid. Freedom Sounds: Civil Rights Call Out to Jazz and Africa. New York, New York: Oxford University Press, 2007.

Nettl, Bruno. The Study of Ethnomusicology: Thirty-one Issues and Concepts. Urbana, Illinois: University of Illinois Press, 2008.

Pettinger, Peter. Bill Evans: How My Heart Sings. New Haven, Connecticut: Yale Nota Bene, 2002.

Porter, Lewis. John Coltrane: His Life and Music. Ann Arbor, Michigan: University of Michigan Press, 1999.

Rosenthal, David H. Hard Bop: Jazz \& Black Music, 19551965. New York, New York: Oxford University Press, 1992.

Stein Crease, Stephanie. Gil Evans: Out of the Cool: His Life and Music. Chicago, Illinois: A Cappella Books, 2002.

Stewart, Jesse. "Freedom Music: Jazz and Human Rights," in Rebel Musics:Human Rights, Resistant Sounds, and the Politics of Music Making. Daniel Fischlin and Ajay Heble, eds., Montreal, Quebec: Black Rose Books, 2003. pp. 88-107.
Turino, Thomas. Music as Social Life: The Politics of Participation. Chicago, Illinois: The University of Chicago Press, 2008.

\section{Journal Publications and Magazine Articles}

Author Unknown. "Jazz World Mourns Loss Of Charlie Parker," in Down Beat Magazine, April 20, 1955, (Vol. \& No. unknown), pg. 5.

Author Unknown. "Third Annual Critics' Poll," in Down Beat Magazine, August 25, 1955 (Vol. 22, No. 17), pg. 9.

DeVeaux, Scott. "Constructing the Jazz Tradition: Jazz Historiography," in Black American Literature Forum 25:3 (Literature of Jazz Issue - Autumn, 1991), pp. 525560. <http://www.jstor.org/stable/3041812> accessed: 09/01/2009.

Feather, Leonard. "No More Agony: Parker Finally Finds Peace," in Down Beat Magazine, April 20, 1955, (Vol. \& No. unknown), pg. 6.

Hentoff, Nat. "Miles," in Down Beat Magazine, November 2, 1955 (Vol. 22, No. 22), pg. 13.

Monson, Ingrid. "The Problem with White Hipness: Race, Gender, and Cultural Conceptions in Jazz Historical Discourse" in Journal of the American Musicological Society 48:3 (Music Anthropologies and Music Histories - Autumn, 1995), pp. 396-422. <http://www.jstor.org/stable/3519833> accessed: 09/01/2009.

Tracy, Jack. "Newport!" in Down Beat Magazine, August 24, 1955 (Vol. 22, No. 17), pg. 24.

\section{Other}

Author Unkown.'Round About Midnight CD Liner Notes (New York, New York: Columbia Records, 2001).

Burns, Ken. "Dedicated to Chaos." Jazz. Episode 7. PBS Home Video (DVD), 2000.

Burns, Ken. "Risk." Jazz. Episode 8. PBS Home Video (DVD), 2000.

\section{Audio Recordings \\ (Listed by appearance in citation and as on Audio Appendix)}

"Move" (D. Best) by Miles Davis Nonet, from The Birth of the Cool (Capitol Records, recorded 1949).

"Jeru" (G. Mulligan) by Miles Davis Nonet, from The Birth of the Cool (Capitol Records, recorded 1949). 
"Now's The Time" (C. Parker) by Charlie Parker Quintet, from Bird: The Savoy Recordings, Vol. 1 (Columbia Records, recorded 1944).

"Walkin"” (R. Carpenter) by Miles Davis All-Stars, from Walkin' (Prestige Records, recorded 1954).

"'Round Midnight" (T. Monk) by Miles Davis Quartet. Recorded Live at $2^{\text {nd }}$ Annual Newport Jazz Festival, Newport, Rhode Island, Sunday, July 17, 1955. Recording found on 'Round About Midnight Legacy Edition (Columbia Records, 2005).
“"Round Midnight" (T. Monk) by Miles Davis Quintet, from 'Round About Midnight (Columbia Records, recorded 1955).

"'Round Midnight" (T. Monk) by Miles Davis Quintet, from The Legendary Prestige Quintet Sessions, Disc 4 (Universal Music Group, 2006). Date of recording unknown, year of recording: 1955 or 56.

"Blues For Pablo" (G. Evans) by Miles Davis and Gil Evans Ensemble, from Miles Ahead (Columbia Records, recorded 1957). 